\title{
Professional Communication Skills in English for Non-native English Speaking Engineers: Challenges and a Proposed Teaching Framework
}

\author{
Deler Singh, Gurvinder Kaur
}

\begin{abstract}
Communicating effectively in English does not come naturally to undergraduate engineering students in India and presumably everywhere where English is not the first language or the mother tongue. In India, English is used as official language in most of the states. It is also the medium of instruction in most educational institutes. Teaching methods and objectives to be achieved while imparting knowledge of English language mainly focus on ability of students to reproduce the learned facts in written form in the examination. Focus on the oral communication and development of English as a medium to share and express original ideas is not really observed at school or university level. Employers worldwide have acknowledged that the conventional engineering curriculum that is focused on imparting technical knowledge has proved to be inadequate in equipping engineers with the adequate employability skills. The objective of this paper is to present a framework for design, teaching and evaluation of a course on communication skills/professional communication for engineering students. A proposed pedagogical framework has been discussed and illustrated as appendices. Guidelines regarding improving communication skills have been made keeping in mind that rather than emphasizing upon incorporating a course on communication skills in the engineering education, communication should be made an integral part of the curriculum.
\end{abstract}

Keywords : Pedagogy, interpersonal communication, communication barriers, Intercultural differences; Group discussion; Interviews; Blog writing; Panel discussions.

\section{INTRODUCTION}

Most organizations, especially in Asian countries, consider English language proficiency as one of the major criteria for the recruitment purpose (Ayokanmbi, 2011; Pratoomrat \& Rajprasit, 2014; Marina \& Rajprasit, 2014). With respect to employability of Indian engineers, Mehra and Virgandham (2013) highlight the relevance of communication skills that include oral, written, interpersonal and listening skills along with confidence. India's employability solutions company Aspiring minds' (2016) employability report observes that merely $17.91 \%$ of engineers are employable for the software services sector, $3.67 \%$ for software products and $40.57 \%$ for

Revised Manuscript Received on September 25, 2019

* Correspondence Author

Dr Deler Singh, Assistant Professor, School of Humanities and Social Sciences, Thapar Institute of Engineering and Technology University, Patiala, Punjab, India

Dr Gurvinder Kaur, Assistant Professor, School of Humanities and Social Sciences, Thapar Institute of Engineering and Technology University, Patiala, Punjab, India a non-functional role such as Business Process Outsourcing. The parameters chosen to ascertain employability in AMCAT (Aspiring Minds Computer Adaptive Test) mention English Communication as its first and one of the most important components. Another such survey conducted by Robert Hall International amongst 1,000 employers in the United States revealed that $96 \%$ of the executives voiced the need of effective communication skills to excel in career (Fisher, 1998). Even companies that provide training after the recruitment, report that approximately $52.21 \%$ engineers are rejected by recruiters because they are not soft skill trainable in a short period of time and within two years of the job, the candidate will have to communicate with international customers. Studies by Blom \& Saeki (2010), report that employers perceive soft skills more important than professional skills. The wall street Journal mentions leadership and communication skills as unwritten requirements that are most in demand and are necessary to stand out from the competition (Perry, 2002). The problem of poor English communication skills leads to unemployment among engineers as they are unwilling to take up jobs that do not conform to their educational standards (Puranik, 2015). As a medium to share the technical knowledge, English language is regarded as the first language of Engineering (Ayokanmbi, 2011; Raina \& Pande, 2012; Gimenez, 2014; Thakur, Kaur, Thakur, \& Nanda, 2013; The Japan Times, 2009). Scientists and engineers need to convince coworkers, clients, and supervisors of their technical skills which may otherwise go unnoticed, irrespective of their technical brilliance and creativity (Huckin \& Oslen, 1991). This is achievable only through effective communication and persuasive skills. Communication skills are therefore considered critical for success and survival in real world environments (Blom \& Saeki, 2011).

Use of English in India for day to day transactions is very limited. Even the students in most of the institutes of higher education use vernacular with a smattering of English or 'Hinglish' - a mixed form of Hindi and English which though acceptable in dining room discussions, leads to dilution of professional impact of both the languages. In spite of being a part of Indian education system for more than a century, English is still beyond the reach of many young people. In spite of sound technical knowledge and valuable work experience, the lack of communication skills may lead to misunderstandings and

frustration in any communicative event (Hart-Rawang \& Li, 2008; 
Laohachaiboon, 2011; Joungtrakul, 2013). Lack of basic language skills has been noted to have affected the development of other skills such as note-taking, summarizing, synthesizing, critical thinking, paraphrasing, etc. (Tahaineh, 2010; Tanaka, 2002).

Accreditation parameters adopted by NBA (2017) suggest that along with the discipline specific efficiencies, an engineering graduate should also be efficient in the following areas: (a) Individual and Team Work: Function effectively as an individual, and as a member or leader in diverse teams, and in multidisciplinary settings; (b) Communication: Communicate effectively on complex engineering activities with the engineering community and with society at large, such as being able to comprehend and write effective reports and design documentation, make effective presentations, and give and receive clear instructions. ABET (2017) also recommends in its accreditation criteria that an engineering student should show ability to function on multidisciplinary teams, an understanding of professional and ethical responsibility and an ability to communicate effectively.

The communication skills are not limited to having command over the language but also imply that students are able to analyze concepts and use their knowledge across the disciplines. The training in communication and professional skills are expected to transcend beyond its transactional function to reflective one. Also, engineering graduates are expected to be globally competent and have a sound knowledge of intercultural nuances. Studies by Craig (2008) specify some nontechnical skills expected of engineers that are teamwork skills, written and oral communication skills, presentation and selling skills, understanding of economics, business and travel etiquette, managing without authority, and leadership with a global view. All these factors make professional and communication skills an imperative tool and requirement for a successful career in engineering.

\section{CURRENT TEACHING FRAMEWORK AND CHALLENGES}

In Indian context, there are many factors that contribute to a lack of professional communication skills in English. As is obvious, many factors are demographic; with $70 \%$ population living in the rural areas (The Hindu, 2015), competence in English is an obvious handicap. It is compounded by lack of good schools at the primary and intermediate level. The students lack efficiency in speaking as well as written skills. Even if English is being taught as a compulsory subject, curriculum at $10+1$ and $10+2$ levels reveals that most of the evaluation components are based on the assessment of written work only and not spoken. There is also a trend of dummy schooling in India where students get enrolled in schools but go to the coaching Institutes to prepare for the very tough IIT-JEE Entrance Examination (Garg, 2017). This examination does not have any section to test capability in English language. Hence, the English skills, if any, gathered over the years in schools are eroded and diluted.

In most of the institutions, it is believed that it is the task of the language/ professional communication skills teacher only to focus on the written/oral use of language by a student. In most of the professional communication courses designed for engineering students, the success of the students is measured mostly in form of written reports or power point presentations which are usually copied by the students. The components to assess oral communication, although present, are not adequate. Unlike the native English speakers who face problems in writing technical documents, Indian students find it daunting to speak even grammatically correct English with the correct pronunciation.

In order to understand and exemplify the issues pertaining to present communication skills/professional communication teaching system in India, this study has taken up the teaching framework adopted by Thapar Institute of Engineering and Technology, Patiala, Punjab, India, that ranks 23rd in India and has an intake of 2000 students/ year. A course on Professional Communication, compulsory for all branches of engineering, covers a wide range of oral as well as written exercises that are covered in a period of one semester only. The course is taught in Lectures and Tutorials in the following manner:

\subsection{Lectures}

The course begins with a focus on the meaning and basic concepts of interpersonal communication, the barriers involved in it, the feedback process and the theories of communication. Nonverbal communication and body language are covered in the next section. The technical writing section of the same course deals with basics of technical writing, different forms of writing, abstraction and summarization, report and proposal writing, résumé and letter writing. Instructions regarding public speaking exercises, panel discussion and making power point presentations are also imparted in the lecture classes. Public speaking (2-3 minutes individual presentations) and panel discussion are practiced and performed in front of the larger group in lectures to remove stage fright among students. The effective number of lectures per semester is around 32 .

\subsection{Tutorials}

The tutorial classes start with Group Discussions, where students get three practice sessions followed by one evaluative session. Making and delivering power point presentations with audio visual aids is the second component where students are trained to prepare power point presentations, master body language and handle stage fright. Report making is the next component where students are supposed to make a report on the topic assigned to the student in consultation with class teacher, which is based on a survey to be conducted by the students.

Students get detailed instructions and assistance from the teachers but the confidence, understanding of the topic and attaining persuasive qualities cannot be perfectly achieved in the short span of the semester. During practice sessions, most of the students have been observed making efforts to overcome their hesitation and nervousness due to their discomfort with language. There has also been observed reluctance in many students to participate in oral communication activities which is the direct result 
of low confidence and insufficient language skills. Appropriate analysis of the topic of discussion and understanding of techniques involved remain a distant dream for most of the students. Although this course covers most of the basic skills recommended for engineering students in lectures and tutorials, it spans over a short period of one semester which has four months. Because of the shortage of time, the opportunities that students get to understand the instructions, assimilate them in their behavior and demonstrate during evaluations are insufficient. They are given extensive feedback during their performances but the students do not really get sufficient chances to work on that feedback and perform again. Because of these constraints, students focus on rote learning, reproduction of crammed facts and copying from the internet.

\section{PROPOSED APPROACH}

The proposed approach has been suggested keeping in mind the needs of students of Indian origin or any other non-native speakers of English. Though the course intends to include comprehensive skills in all the semesters, the emphasis however in the first semester should be on developing oral skills; gradually moving onto writing skills in the second semester and finally to reflective and analytical skills in third semester (See appendices attached).

As already mentioned, Indian students face more difficulty in oral communication, therefore, the course may be started with a heightened focus on improving oral skills. Britton identifies three different kinds of language use by the students; expressive language, he says, is language close to the self; it reveals as much about the speaker as it does about the topic...Transactional language, on the other hand, is language for an audience. Its primary aim is to convey information clearly to other people; it is the language of newspapers, law courts, and technical reports. It is also the language of schools [Freisinger, 1982]. The evaluation of the students' learning in the engineering institutes is usually made on the basis of transactional language capabilities rather than expressive language which should be the focus. When the students in the beginning of the course realize that their evaluation will be based upon what they reproduce on the paper in the examination, the conceptual understanding and learning take a backseat. Language must be employed in classrooms as a tool for discovery, an aid to learning, not merely as an instrument for reporting [Freisinger, 1982]. For this purpose, the activities focusing on developing interpersonal oral communication skills such as telephonic conversations/etiquette, role play acts (introducing each other, your dream career, nickname game, creative fairy tales, rumors, etc.) may be taken up in the beginning of the course. During oral presentations also, the focus should be more on the pronunciation, grammatical accuracy and appropriate use of body language. Public speaking exercises (two minutes individual presentations) should be done initially in front of a small group in the beginning and later in front of larger group in order to make students comfortable addressing the audience. In the second semester, public speaking maybe carried out in mixed batches to expose students to relatively unfamiliar audience.

To provide extra assistance to the weaker students (students who have studied physics, chemistry and mathematics in
Hindi/regional language till 10+2 level), lab component may be introduced. In the labs, a consolidated communication package may be offered where the students can anonymously choose the package from beginners to advance level in order to avoid any feeling of inferiority. All the students after a few self-study sessions may be asked to clear a common test which may be conducted as per the level of the students. The written exercises in the first semester may be introduced beginning with the basic principles of writing technical documents. Writing letters and résumé may be taught along with the basic formats of memos, reports and proposals. The detailed course on technical report writing with a focus on research may be introduced in the second semester (See Appendices).

Observations reveal that skills achieved in dedicated courses are not necessarily transferred to other contexts. Also, faculty from other disciplines are hesitant to grade communication skills due to a perceived lack of language expertise or because they find the task tedious. In order to solve the problem, rather than making it a standalone course, the professional communication course may be integrated with other core disciplines and coordination from other departments may be sought. For example, the students may be involved in maintaining their individual blogs which they need to update every week. They may be helped by computer science teachers in maintaining the blog, while the writing and content feedback and assistance may be provided in Professional communication classes. Every student may be asked to speak for a minute or two about his blog which will take care of oral as well as their written communication skills.

While making the reports, the students may be asked to identify their areas of interest from their respective fields and work on them. The students may be asked to write reviews of research papers related to their discipline, analyze them orally in the groups where the peer feedback may be considered. Mock interviews with the assistance of core courses' teachers and placement cell may be conducted. Subject specific seminars may be organized with every student participating in a minimum number of seminars per semester as per his choice and orientation. The evaluation for such activities may be carried out collectively by professional communication and subject specific faculty. The importance of group working skills is recognized across the disciplines. These skills may be improved through peer feedback and evaluation system which helps the students develop better understanding and explanation of a concept, speak confidently and effectively and develop group dynamics.

Once the students have achieved oral and written proficiency, the focus should be to help them develop skills related to global competence by introducing them to issues such as intercultural communication, entrepreneurship, leadership lessons, startup success stories in India and abroad, business ethics, etc. The evaluation, understanding and reflection on these concepts help engineering students to develop critical thinking and also provide them an early exposure to the issues outside their domain. In this course, the focus may be equally 
divided into the written and spoken parts. Case studies from literature, films, TV series, autobiographies, individual success stories etc., maybe used to teach concepts however the students should be given freedom in choosing the case studies for themselves on the basis of their understanding and interests.

\section{TEACHING AND EVALUATION METHODS}

In the first semester, more of weightage should be assigned to oral communication components than written (70 oral: 30 written). In the subsequent two semesters, it should be equal (50:50). The students may be taught the theoretical concepts regarding the meaning and importance as mentioned in the course curriculum in the lecture classes, while the practice and discussions related to their practical usage may be done both in lectures as well as tutorials (See Appendices).

For tutorial evaluations, where the students' participation and involvement is more, the activities that are group based may be conducted. The examples of such activities are role play, panel discussions on current topics and improvisation, etc., which provide every individual in the group an opportunity to speak. Group activities are emphasized upon in the beginning to avoid the nervousness and low confidence that arises in case of individual activities because of the focus of the entire group on an individual. Without proper training and practice, individual activities may lower the confidence of an individual greatly if he/she does not perform well. The individual activities such as public speaking (1-2 minutes) may be started after some time in the tutorial classes (smaller groups) which may be performed and evaluated in the lecture classes (larger groups) later on. The Group Discussions may be introduced in the first semester only but the evaluation for the same maybe done in the next semester when the students are better equipped to participate.

The concept of peer feedback and evaluations will be introduced from the first semester only. Apart from promoting group dynamics and healthy participation, peer evaluation improves students' analytical skills and understanding of concepts as they focus more when they know their feedback matters. The feedback may be taken both in oral as well as written form. The weightage of peer evaluation in the final score may be decided by the teacher. The viva-voce examination should be an integral part of evaluation in all three semesters. Excessive written evaluations at times promote practices like copying among students which may be taken care of through viva-voce exams as viva encourages students to study a concept on a deeper level. Viva-voce should be a significant component of evaluation of PowerPoint presentation in all three semesters. The teaching of report writing in the lecture classes must be accompanied by actual report making in the tutorial classes. The evaluation of reports should also carry a viva-voce component. The concepts of intercultural communication, leadership, entrepreneurship and business ethics should be taught in the lecture classes and the case studies related to the concepts should be discussed in the tutorial classes. The evaluations in this module may be continuous in the form of oral and written examinations and quizzes.

\section{RESULTS}

The training rooted in methods mentioned above has been reported to improve communication abilities of the students. It makes students understand transactional as well as reflective functions of the language. The students may be expected to perform better in different communicative events. By providing them more opportunities to speak and participate in different situations, the problems related to their hesitation may be solved. Peer feedback makes them understand the evaluation criteria better and also helps improve their oral communication skills. Peer feedback has also been reported to improve social and interpersonal skills of the students. Group discussions on current topics help develop students' critical thinking abilities.

\section{CONCLUSION}

Language and communication skills are recognized as important elements in the education of modern engineer and the institutions that have already implemented communication and soft skills elements will be at the forefront of fulfilling the demands of the industry and the society [Riemer 2002]. There is ample evidence that teaching and learning about professional communication skills (presenting proposals, writing reports, email messages, calling for meetings, documenting team work decisions) out of their appropriate settings does not guarantee full student involvement in the learning process and may be ultimately futile [Mercer, 2006; Yu, 2008; Chun, 2010]. If these skills are contextualized within the engineering projects such as-choice of project, making its proposal, writing the report, submission, and poster presentation-they can increase students' involvement and overall performance.

\section{REFERENCES}

1. ABET. Criteria for Accrediting Engineering Programs, 2016-2017. Retrieved from http://www.abet.org/accreditation/accreditation-criteria/criteria-for-accre diting-engineering-programs-2016-2017/\#students.

2. Aspiring minds Employability Quantified, National employability report-Engineers Annual report 2016. Retrieved from http://www.aspiringminds.com/research-reports. Accessed on 15 May 2017.

3. Ayokanmbi, F. M. (2011). Competencies for global engineers and technologists. Journal of Industrial technology, 27(1), 1-6.

4. Blom, A \& Saeki, H. (2011) Employability and Skill Set of Newly Graduated Engineers in India. The World Bank.

5. Chun, M. (2010). Taking teaching to (performance) task: Linking pedagogical and assessment practices. Change, 42(2), 22-29.

6. Craig, W. O. Preparing the Engineering Technology Graduate for the Global Marketplace. The Technology Interface Journal, 10 (3), 2008.

7. Fisher, Ann. (1998). The High Cost of Living and Not Writing Well. Fortune, 244.

8. Gimenez, J. (2014). Multi-communication and the business English class: Research meets pedagogy. English for Specific Purposes, 35, 1-16. http://dx.doi.org/10.1016/j.esp.2013.11.002

9. Hart-Rawung, P., \& Li, L. (2008). Globalization and business communication: English communication skills for Thaia utomotive engineers. World Academy of Science, Engineering, and Technology, 24, 320-330.

10. http://www.tribuneindia.com/news/bathinda/dummy-admissions-on-risein-city/389107.html

11. Huckin, Thomas N. \& Olsen, Leslie A. (1991). Technical Writing and Professional Communication for Nonnative Speakers of English. New York: McGraw-Hill International. 
12. Joungtrakul, N. (2013). Thai engineers' readiness to cope with the free flow of skilled labor in the ASEAN Economic Community. HRD Journal, 4(1), 6-21.

13. Laohachaiboon, S. (2011). Intercultural communication obstacles in a Japanese company: a case study into cross-cultural effect and difficulties in English communication of Thai employees at Toyota Tsusho (Thailand) Co., Ltd. (Unpublished master's thesis). Thammasart University, Bangkok, Thailand.

14. Marina, O. \& Rajprasit, K. (2014). Investigating the impact of personality factors on perceived communication mobility of non-native English speaking Thai professionals in international companies. PASAA, 47, 61-96.

15. Mehra, D. \& Virgandham, V. (2013). Communication skills for enhanced employability of engineers: A review of literature. The Confluence Journal, 3, 70-76.

16. Mercer, J. A. A. (2006). Madness to our method: Congregational studies as a cross-disciplinary approach to contextualizing teaching and learning in theological education. Teaching Theology and Religion, 9(3), $148-155$.

17. National Board of Accreditation. (2012). Manual for accreditation of Engineering Graduate Programs. Retrieved from www.nbaind.org/Files/engineering-programs.pdf.

18. Perry, D. (2002). Do you Have the Skills Most in demand Today? Career Journal from the Wall Street Journal. Retrieved from http://www.careerjournal.com/columnist/perspective/20020520-fmp.ht $\mathrm{ml}$.

19. Puranik, A. (2015, August 11). 97\% engineering graduates cannot speak English fluently: Survey. Retrieved from http://www.hindustantimes.com/education/97-engineering-graduates-ca nnot-speak-english-fluently-survey/story-GQEkTYwI4AX5zc7oeXkz1 M.html.

20. R. Freisinger. (1982). The Personal Connection: Journal Writing across the Curriculum in Fulwiler, T. \& Young, A. (eds), Language Connections: Writing and Reading Across the Curriculum, National Council of Teachers of English, Illinois.

21. Raina, R. \& Pande, N. (2012). Communication competence of Indian engineers in IT \& ITeS sector. The Indian Journal of Industrial Relations, 47(3), 511-526.

22. Rajprasit, K., Pratoomrat, P., Wang, T., Kulsiri, W., \& Hemchua, S. (2014). Use of the English language prior to and during employment: Experiences and needs of Thai novice engineers. Global Journal of Engineering Education, 16(1), 27-33.

23. Riemer, M.J. (2002). English and communication skills for the global engineer. Global Journal of Engineering Education, 6(1), 91-100.

24. Tahaineh, Y.S. (2010). Arab EFL university students' errors in the use of prepositions. MJAL, 2(1), 76-112.

25. Tanaka, J. (2002). Academic difficulties among East Asian international graduate students: influences of perceived English language proficiency and native educational/sociocultural background. (PhD's thesis). Indiana University.

26. Thakur, S., Kaur, S., Thakur, P. V., \& Nanda, D. R. (2013). English teaching to engineering students difficulties and solutions. Journal of Literature, Languages and Linguistics, 2, 55-59.

27. The Hindu. (2016, October 01). About 70 percent Indians live in rural areas: Census report. Retrieved from http://www.thehindu.com/news/national/About-70-per-cent-Indians-livein-rural-areas-Census-report/article13744351.ece.

28. The Japan Times. (2009). Japan Times Forum on English Education: Engineers Must Have English Skills to Succeed. Retrieved from http://www.sci.kanagawa-u.ac.jp/pdf/2009_times01.pdf.

29. The Tribune. (2017, April 9). Dummy Admissions on Rise in city. Retrieved from Yu, H. (2008). Contextualize technical writing assessment to better prepare students for workplace writing: Student-centered assessment instruments. Journal of Writing and Communication, 38(3), 265-284. 